\title{
Southeast Asian Isolate of the Tomato Leaf Curl New Delhi Virus Shows Higher Pathogenicity Against Tomato and Cucurbit Crops Compared to that of the Mediterranean Isolate
}

\author{
Hiroto Yamamoto ${ }^{1}$, Yuya Wakita ${ }^{2}$, Toshiya Kitaoka ${ }^{2}$, Kohei Fujishiro ${ }^{2}$, Elly Kesumawati ${ }^{3}$ \\ and Sota Koeda ${ }^{1,2 *}$
}

${ }^{1}$ Graduate School of Agriculture, Kindai University, Nara 631-8505, Japan

${ }^{2}$ Faculty of Agriculture, Kindai University, Nara 631-8505, Japan

${ }^{3}$ Faculty of Agriculture, Syiah Kuala University, Darussalam, Banda Aceh 23111, Indonesia

The tomato leaf curl New Delhi virus (ToLCNDV) is a bipartite begomovirus (genus Begomovirus, family Geminiviridae) that was originally isolated in India, but has become a serious threat to various horticultural crops in the Indian subcontinent, Southeast Asia, East Asia, Middle East, and western Mediterranean Basin. In Southeast Asia, East Asia, and the western Mediterranean Basin, ToLCNDV has caused huge economic damage to cucurbit crops (cucumber, melon, squash, and zucchini) for which commercial ToLCNDV-resistant cultivars are currently unavailable. In this study, full-length ToLCNDV viral sequences were isolated from cucumber, melon, and zucchini plants exhibiting yellow leaf curl disease in Almeria, Spain. Phylogenetic analysis showed that the isolated viruses consisted of the ToLCNDV-ES strain and strains that were genetically distant from ToLCNDV-[BACu-20] in Southeast Asia, which were previously isolated in the Aceh province of Indonesia. Infectious clones of ToLCNDV-[ES-AIm-Cuc-16] from Spain and of ToLCNDV-[BACu-20] from Indonesia were prepared, and ToLCNDV isolates were agroinoculated to Nicotiana benthamiana, tomato, and cucurbit crops (cucumber, melon, and zucchini). Infection rates were nearly $\mathbf{1 0 0 \%}$ for all inoculated plant species, and disease symptoms were consistently more severe in plants inoculated with ToLCNDV-[BACu-20] compared to plants inoculated with ToLCNDV-[ES-Alm-Cuc-16]. For tomatoes inoculated with ToLCNDV[ES-Alm-Cuc-16], infection occurred without symptoms in most plants, and only a few plants showed slight vein-yellowing symptoms. In contrast, ToLCNDV-[BACu-20] infection induced typical begomoviral disease symptoms of yellowing and curling of leaves in the same tomato cultivar. The present study highlights the importance of screening genetic resources for ToLCNDV resistance by using ToLCNDV isolates from the intended production area; furthermore, the agroinoculation method used in this study will facilitate breeding resistance against both the Southeast Asian and Mediterranean ToLCNDV isolates.

Key Words: agroinoculation, begomovirus, geminivirus, horticultural crop, ToLCNDV.

\section{Introduction}

The genus Begomovirus of the Geminiviridae family encompasses 424 virus species (ICTV), which are composed of circular and single-stranded DNA genomes encapsulated in twinned icosahedral particles and rely on whitefly (Bemisia tabaci) vectors for plant-to-plant

Received; December 10, 2020. Accepted; March 17, 2021.

First Published Online in J-STAGE on May 11, 2021.

This study was supported by the Japan Society for the Promotion of Science (JSPS) KAKENHI Grant number 19H02950 to S. Koeda.

* Corresponding author (E-mail: 818sota@nara.kindai.ac.jp). transmission. Most begomoviruses exhibit bipartite genomes composed of two circular DNA components (DNAs A and B) of approximately 2,800 nucleotides each (Hanley-Bowdoin et al., 2013). In contrast, monopartite begomoviruses have only one DNA component, which is an A-like genome. The disease caused by begomovirus has emerged as a serious constraint to the cultivation of a wide variety of vegetable crops worldwide (Navas-Castillo et al., 2011).

Tomato yellow leaf curl virus (TYLCV), a monopartite begomovirus, is a plant-infecting virus of high economic and scientific importance (Scholthof et al., 2011). The first report of TYLCV was on infected 
tomato plants in Israel (Cohen and Nitzany, 1960, 1966). TYLCV now has a distribution encompassing regions in the Middle East, Western Mediterranean, North Africa, East Asia, Caribbean, North America, Central America, and Australia, where it significantly affects tomato production (Mabvakure et al., 2016).

Tomato leaf curl New Delhi virus (ToLCNDV) is a bipartite begomovirus that infects Solanaceae crops (tomato, pepper, eggplant, and potato) and cucurbit crops (cucumber, melon, zucchini, and luffa) (Moriones et al., 2017; Zaidi et al., 2017). ToLCNDV is a begomovirus species that has high economic importance in horticultural production. ToLCNDV was first reported in India in 1995, and its distribution has been documented across the Indian subcontinent (India, Pakistan, and Bangladesh), Southeast Asia (Thailand and Indonesia), and East Asia (Taiwan) (Chang et al., 2010; Hussain et al., 2004; Ito et al., 2008; Maruthi et al., 2005; Mizutani et al., 2011; Padidam et al., 1995). In Asia, ToLCNDV has affected mainly cucurbit crops, including cucumber (Cucumis sativus), melon (C. melo), squash (Cucurbita spp.), bottle gourd (Lagenaria siceraria), Luffa spp., and Sechium edule. (Chang et al., 2010; Ito et al., 2008; Nagendran et al., 2017; Phaneendra et al., 2012; Sohrab et al., 2003). Since 2012, ToLCNDV has spread westward, with reports from the Middle East, Spain, Portugal, Italy, Greece, Morocco, Tunisia, and Algeria in the Mediterranean Basin (EPPO, 2020; Juárez et al., 2014; Kheireddine et al., 2019; Mnari-Hattab et al., 2015; Orfanidou et al., 2019; Panno et al., 2016; Ruiz et al., 2015; Sifres et al., 2018; Yazdani-Khameneh et al., 2016). Since the first report, ToLCNDV outbreaks have significantly affected cucurbit production in Almeria, Murcia, and Malaga in the Andalusia region of southern and southeastern Spain (Juárez et al., 2014, 2019). Almeria has built the largest concentration of greenhouses in the world, where the production of tomato (10,232 ha), sweet pepper (8,406 ha), zucchini (6,358 ha), watermelon (5,665 ha), cucumber (4,920 ha), melon (3,740 ha), eggplant (2,006 ha), and green bean $(1,283$ ha) (Valera et al., 2016) could suffer tremendous economic loss due to infection by the ToLCNDV pathogen.

The main approach for the management of begomovirus diseases is to use insecticides that reduce vector populations; however, intensive and unregulated use of insecticides results in insecticide resistance or reduced susceptibility of the vector (Palumbo et al., 2001; Rojas et al., 2018). An effective alternative to an integrated pest management approach for begomovirus control is the development of genotypes that are resistant to begomoviruses. Breeding for begomovirus resistance is the most advanced in tomatoes. The six major identified loci $(T y-1-T y-6)$ for resistance to TYLCV originate from wild relatives (Agrama and Scott, 2006; Anbinder et al., 2009; Hutton and Scott, 2014; Ji et al., 2009a, b;
Zamir et al., 1994), and introgression into the cultivated tomato has been a major focus of breeding programs (Yan et al., 2018). Although several studies have reported the resistance of melon, C.moschata, and L. cylindrica accessions against ToLCNDV (Islam et al., 2010; López et al., 2015; Sáez et al., 2016), resistance to begomovirus infection is much less advanced in cucurbit crops compared to that of tomato. As yet, no commercial cultivars carry resistance to the begomovirus infection.

More than 500 DNA-A full-length sequences of ToLCNDV are stored in the GenBank database. Phylogenetic analysis of ToLCNDV Mediterranean isolates have shown that these isolates have 91\%-94\% DNA-A similarity to other ToLCNDV isolates; they should be categorized as a different strain and named ToLCNDV$\mathrm{ES}$, according to the taxonomic rule for begomoviruses (Brown et al., 2015; Fortes et al., 2016). Interestingly, while ToLCNDV isolates from India infect and cause disease in tomato plants, ToLCNDV-ES has poor infection ability and an absence of symptoms in tomato (Fortes et al., 2016). Considering differences in the host or pathogenicity among ToLCNDV isolates, comparison and characterization of ToLCNDV isolates from different geographic origins could offer important information for breeding of ToLCNDV resistance. As far as we know, the report by Fortes et al. (2016) is the only study that compared and characterized different isolates from Spain and India and there is no report that compared them with the Southeast Asian isolate. In this study, we agroinoculated ToLCNDV-ES and ToLCNDV-[BACu-20] from Indonesia (Kesumawati et al., 2020) and compared its pathogenicity in Nicotiana benthamiana, tomato, and cucurbit crops.

\section{Materials and Methods}

Virus sources, polymerase chain reaction diagnosis, cloning, sequence determination, and sequence analysis

Leaf samples from 6 cucumber (C. sativus), 18 melon (C. melo), and 6 zucchini (C.pepo) plants exhibiting yellowing and/or curling symptoms were collected in Almeria, Spain in 2016 (Fig. 1). Genomic DNA was extracted from the leaves using Nucleon PhytoPure (GE Healthcare, IL, USA). The presence of begomoviral DNA-A was examined by polymerase chain reaction (PCR) using universal primers (Briddon and Markham, 1994). PCR was performed using EmeraldAmp PCR Master Mix (Takara Bio, Shiga, Japan). The reaction mixtures were initially denatured at $94^{\circ} \mathrm{C}$ for $2 \mathrm{~min}$, followed by 35 cycles at $94^{\circ} \mathrm{C}$ for $30 \mathrm{~s}, 60^{\circ} \mathrm{C}$ for $30 \mathrm{~s}$, and $72^{\circ} \mathrm{C}$ for $3 \mathrm{~min}$, terminating with $5 \mathrm{~min}$ of final extension at $72^{\circ} \mathrm{C}$. The amplified PCR products were subjected to electrophoresis using $1.0 \%(\mathrm{w} / \mathrm{v})$ agarose gel. PCR products were digested by BglI and subjected to electrophoresis again.

Full-length begomoviral genomes were amplified from the extracted DNA by rolling circle amplification 


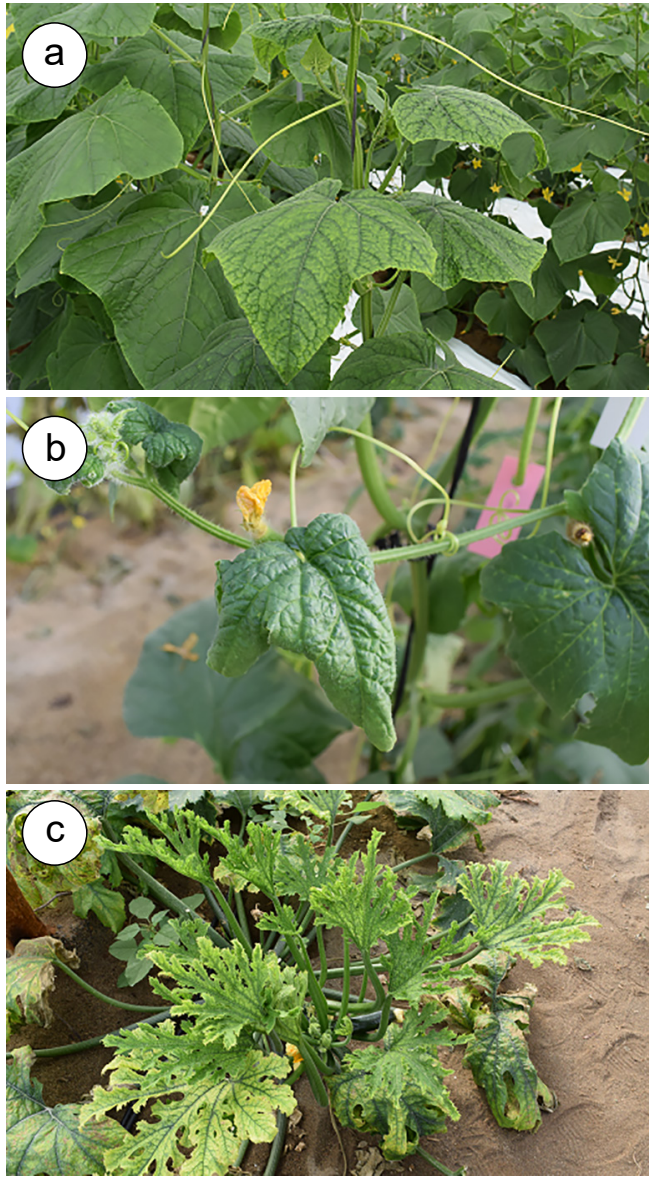

Fig. 1. Yellow leaf curl disease of (a) cucumber, (b) melon, and (c) zucchini observed at Almeria, Spain.

(RCA) using a TempliPhi DNA amplification kit (GE Healthcare). An RCA reaction was performed according to Koeda et al. (2015). The concatemers produced in the reaction were monomerized by restriction digestion with BamHI. Digested products were resolved by electrophoresis using 1\% agarose gel, and the bands that corresponded to $2.8 \mathrm{kbp}$ were purified using a Gel DNA Recovery Kit (ZYMO Research, CA, USA). The $2.8 \mathrm{kbp}$ monomers were cloned into the appropriate site of a pBlueScript II SK (+) vector (Agilent Technology, CA, USA). Monomeric full-length clones were purified using a FastGene ${ }^{\mathrm{TM}}$ Plasmid Mini Kit (Nippon Genetics, Tokyo, Japan). Nucleotide sequencing was conducted in an ABI PRISM 3100 genetic analyzer with an ABI PRISM BigDye Terminator v3.1 Cycle Sequencing Kit (Applied Biosystems, CA, USA) and analyzed by conducting sequence similarity searches using BLASTn. Multiple sequences were aligned using MUSCLE (Edgar, 2004). Pairwise sequence identity comparisons were performed using the Species Demarcation Tool v1.2 program (Muhire et al., 2014). Phylogenetic analysis was conducted in MEGA7 using the neighbor-joining method (Kumar et al., 2016). A bootstrap consensus tree was inferred from 1000 replicates.

\section{Construction of infectious clones}

Full-length DNA-A and DNA-B sequences of ToLCNDV-[ES-Alm-Cuc-16] (DNA-A: LC596380, DNA-B: LC596383) and ToLCNDV-[BACu-20] (DNA-A: LC511775, DNA-B: LC511780) were cloned into pGreenII-p35S according to Koeda et al. (2017). The obtained constructs were named pGreenII-p35SToLCNDV-[ES-Alm-Cuc-16]-DNA-A, pGreenII-p35SToLCNDV-[ES-Alm-Cuc-16]-DNA-B, pGreenII-p35SToLCNDV-[BACu-20]-DNA-A, and pGreenII-p35SToLCNDV-[BACu-20]-DNA-B. To clone both DNA-A and DNA-B of ToLCNDV in the same pGreenII-p35S vector, the DNA-B partial repeats in pGreenII-p35SToLCNDV-[ES-Alm-Cuc-16]-DNA-B and pGreenIIp35S-ToLCNDV-[BACu-20]-DNA-B were amplified by PCR. Amplified fragments and p35S-ToLCNDV[ES-Alm-Cuc-16]-DNA-A or pGreenII-p35SToLCNDV-[BACu-20]-DNA-A cut by SmaI were ligated using an In-Fusion HD Cloning Kit (Takara Bio). The obtained constructs were named pGreenIIp35S-ToLCNDV-[ES-Alm-Cuc-16]-DNA-A+B and pGreenII-p35S-ToLCNDV-[BACu-20]-DNA-A+B. The primer sequences are presented in Table S1.

\section{Inoculation of Nicotiana benthamiana and tomato plants with ToLCNDV}

Agroinfiltration and a colony inoculation procedure were conducted according to the method reported by Koeda et al. (2017). Agroinfiltration to $N$. benthamiana was conducted using pGreenII-p35S (empty), a mixture of pGreenII-p35S-ToLCNDV-[ES-Alm-Cuc-16]-DNA$A$ and pGreenII-p35S-ToLCNDV-[ES-Alm-Cuc-16]DNA-B, or a mixture of pGreenII-p35S-ToLCNDV[BACu-20]-DNA-A and pGreenII-p35S-ToLCNDV[BACu-20]-DNA-B. A colony inoculation procedure for 'Momotaro' (Takii seed, Kyoto, Japan), a begomovirussusceptible tomato cultivar, was conducted using pGreenII-p35S (empty), pGreenII-p35S-ToLCNDV[ES-Alm-Cuc-16]-DNA-A+B, or pGreenII-p35SToLCNDV-[BACu-20]-DNA-A+B. Agrobacterium GV2260 was used for inoculation.

\section{Inoculation of cucurbit crops with ToLCNDV}

Seeds of cucumber 'Natsu Suzumi', melon 'Otome', and zucchini 'Diner' (Takii seed), which are begomovirus-susceptible cultivars, were sown in a horticultural soil mix. Agroinfiltration was applied with 0.3 optical density to cotyledons before the first true leaf was developed using pGreenII-p35S (empty), a mixture of pGreenII-p35S-ToLCNDV-[ES-Alm-Cuc-16]-DNA$A$ and pGreenII-p35S-ToLCNDV-[ES-Alm-Cuc-16]DNA-B, or a mixture of pGreenII-p35S-ToLCNDV[BACu-20]-DNA-A and pGreenII-p35S-ToLCNDV[BACu-20]-DNA-B. For zucchini plants, a colony inoculation procedure was conducted on the hypocotyl just below the apex of the seedlings before the first true leaf was developed using pGreenII-p35S (empty), 
pGreenII-p35S-ToLCNDV-[ES-Alm-Cuc-16]-DNA-A+B, or pGreenII-p35S-ToLCNDV-[BACu-20]-DNA-A+B. Agrobacterium GV2260 was used for inoculation.

\section{Viral DNA detection}

Newly developed upper leaves at 20 or 30 days post inoculation (dpi) were collected from the inoculated plants, and DNA was extracted using a simple DNA extraction method (Koeda and Fujiwara, 2019). DNA-A of ToLCNDV-[ES-Alm-Cuc-16] was detected by a PCR using ToLCNDV A $2 \mathrm{~F}$ and $2 \mathrm{R}$ primers, and DNA$\mathrm{B}$ of ToLCNDV-[BACu-20] was detected using ToLCNDV Uni $\mathrm{F}$ and $\mathrm{R}$ primers (Table $\mathrm{S} 1$ ) (Kesumawati et al., 2020). PCR was performed using EmeraldAmp PCR Master Mix (Takara Bio). The reaction mixtures were initially denatured at $94^{\circ} \mathrm{C}$ for $2 \mathrm{~min}$, followed by 35 cycles at $94^{\circ} \mathrm{C}$ for $30 \mathrm{~s}, 66.5^{\circ} \mathrm{C}$ (ToLCNDV-[ES-Alm-Cuc-16]) or $55^{\circ} \mathrm{C}$ (ToLCNDV[BACu-20]) for $30 \mathrm{~s}$, and $72^{\circ} \mathrm{C}$ for $1 \mathrm{~min}$, and terminating with a 3 min final extension at $72^{\circ} \mathrm{C}$. The amplified PCR products were subjected to electrophoresis using $1.0 \%(\mathrm{w} / \mathrm{v})$ agarose gel. The primer sequences are presented in Table S1.

\section{Results}

Isolation of begomoviral DNAs from cucurbit crops and sequence analysis

In 2016, leaf samples of 6 cucumber, 18 melon, and 6 zucchini plants exhibiting yellowing and curling were collected from Almeria, Spain. Cucumber and zucchini plants showed heavy yellowing in the leaves, and melon had stronger curling in the leaves as opposed to yellowing (Fig. 1). When begomovirus-specific universal primers (Briddon and Markham, 1994) were used for the PCR, the cucumber, melon, and zucchini samples all tested positive for begomovirus infection (Fig. 2a). Moreover, since PCR amplicons digested by BglII had similar band patterns, it was assumed that begomoviruses with high sequence similarity were infectious to these cucurbit crops (Fig. 2b). Furthermore, a single plant from each cucurbit crop was randomly chosen for sequence analysis of full-length begomoviral DNA using the RCA method. From each sample, complete DNA-A and DNA-B sequences were obtained, so a total of three DNA-A sequences and three DNA-B sequences were obtained. When BLASTn was conducted, the obtained DNA-A and DNA-B sequences had high sequence identity of greater than 99\% with ToLCNDV sequences isolated from melon, zucchini, and datura plants at Almeria and Murcia in Spain (Table 1).

Phylogenetic analysis was conducted using the fulllength DNA-A sequences of ToLCNDV from GenBank and sequences obtained in our present and previous studies (Kesumawati et al., 2020). In total, 140 ToLCNDV full-length sequences isolated from the Indian subcontinent (India, Pakistan, and Bangladesh), Southeast Asia (Thailand, Indonesia, Laos, and Cambodia), East Asia (Taiwan), the Middle East (Iran), and the Mediterranean Basin (Spain, Italy, Morocco,

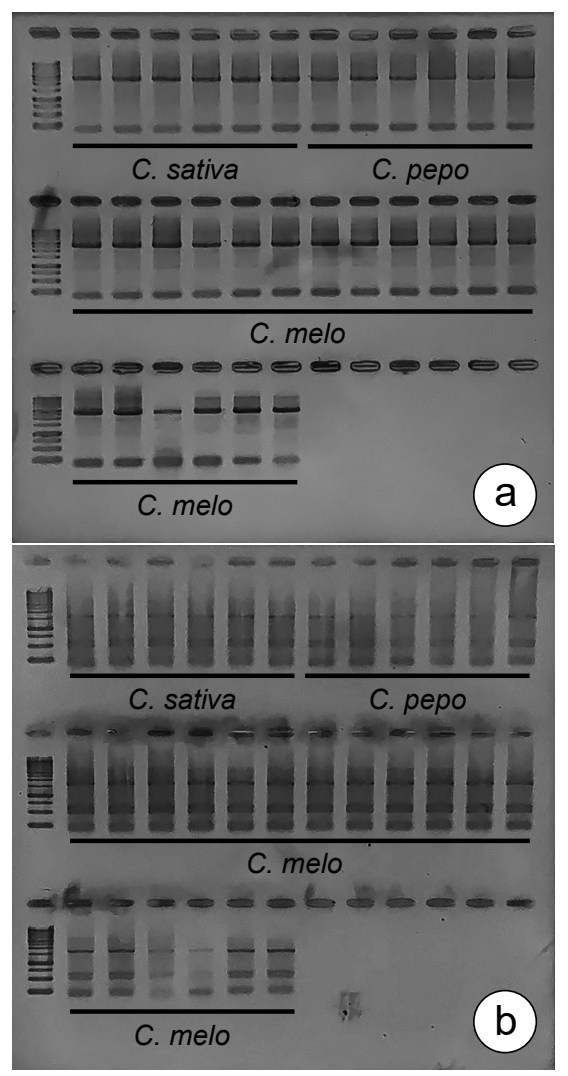

Fig. 2. Diagnosis of begomovirus infection (a) using universal primers for begomovirus and (b) restriction fragment length (RFLP) analysis of the PCR amplicon

Table 1. Identities and sizes of begomoviruses isolated in this study.

\begin{tabular}{cccccccc}
\hline \hline \multirow{2}{*}{$\begin{array}{c}\text { Begomovirus } \\
\text { species }\end{array}$} & Isolate & $\begin{array}{c}\text { DNA molecule } \\
\text { and size (nt) }\end{array}$ & Accession no. & Host & \multicolumn{3}{c}{ Identity } \\
\cline { 6 - 8 } ToLCNDV & [ES-Alm-Cuc-16] & DNA-A (2738) & LC596380 & C. sativus & 99.9 & ToLCNDV & MH577751 \\
& & DNA-B (2684) & LC596383 & & 99.6 & Virus & MH577673 \\
& [ES-Alm-Mel-16] & DNA-A (2738) & LC596381 & C. melo & 99.7 & ToLCNDV & MH577751 \\
& & DNA-B (2684) & LC596384 & & 99.3 & KF749226 \\
& [ES-Alm-Zuc-16] & DNA-A (2738) & LC596382 & C. pepo & 99.9 & ToLCNDV & MH577714 \\
& & DNA-B (2684) & LC596385 & & 99.5 & & MH577645 \\
\hline
\end{tabular}


and Algeria) were used to construct a phylogenetic tree with a bipartite begomovirus, pepper huasteco yellow vein virus (PHYVV) from Mexico, as an outgroup. DNA-A sequences of ToLCNDV isolated from Spain in this study formed a clade with ToLCNDV, which was previously isolated from Spain, Italy, Morocco, and Algeria (Fig. 3). Moreover, these isolates had similarity identities of $91 \%-94 \%$ with other ToLCNDV isolates based on pairwise sequence identity comparison analysis, which revealed that they constituted a previously reported ToLCNDV-ES strain (Fortes et al., 2016) (Fig. S1). DNA-A of ToLCNDV-[BACu-20] isolated from Indonesia in our previous study (Kesumawati et al., 2020) formed a clade with ToLCNDV isolates from Thailand, Indonesia, Laos, Taiwan, and Bangladesh (Fig. 3). However, some of the isolates from India and Bangladesh had greater than 94\% similarity identities (threshold for strain) with these Southeast Asia and East Asian isolates (Fig. S1). From these results, it was concluded that although isolates from Southeast Asia and East Asia have high similarity with each other, they did not constitute a strain. Interestingly, ToLCNDV-[KH_winter melon_Q6568] (MH328257) from Cambodia and ToLCNDV-[LA_luffa_Q6440] (MH328254) from Laos formed a different clade than that of other ToLCNDVs isolated from Southeast Asia and East Asia (Fig. 3). Moreover, these isolates showed similarity identities below 91\% (threshold for species) with all analyzed ToLCNDV sequences (Fig. S1), which revealed that these two isolates may represent a novel begomovirus species. Overall, phylogenetic analysis showed that ToLCNDV isolated from Spain in this study and ToLCNDV-[BACu-20] isolated from Indonesia in our previous study are representative isolates from the Mediterranean Basin and Southeast Asia or East Asia and were genetically distant from each other. The obtained sequences of ToLCNDV-[ES-AlmCuc-16] (DNA-A: LC596380, DNA-B: LC596383), ToLCNDV-[ES-Alm-Mel-16] (DNA-A： LC596381, DNA-B: LC596384), and ToLCNDV-[ES-Alm-Zuc-16] (DNA-A: LC596382, DNA-B: LC596385) were submitted to GenBank.

\section{Inoculation of ToLCNDV isolates to N. benthamiana and tomato plants}

Partial tandem repeats of ToLCNDV DNA-A and DNA-B were constructed, and their infectivity was tested on $N$. benthamiana by agroinfiltration. Inoculation of empty pGreenII-p35S produced no virus symptoms (Fig. 4a; Table 2). In contrast, ToLCNDV-[ES-AlmCuc-16]-inoculated plants started to show symptoms at $7 \mathrm{dpi}$, and all the inoculated plants showed typical begomoviral symptoms at $30 \mathrm{dpi}$ (Fig. 4b; Table 2). ToLCNDV-[BACu-20]-inoculated plants also started to show symptoms at $7 \mathrm{dpi}$, and the disease symptoms were more severe compared to those of ToLCNDV[ES-Alm-Cuc-16]-inoculated plants at $30 \mathrm{dpi}$ (Fig. 4c;

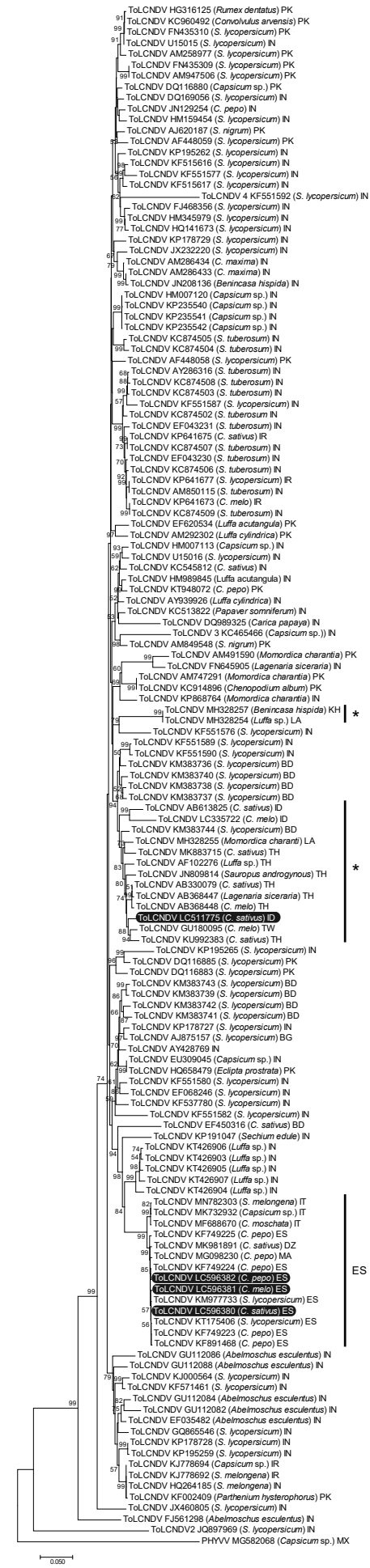

Fig. 3. Phylogenetic tree of tomato leaf curl New Delhi virus (ToLCNDV) DNA-A. The DNA-A sequence of pepper huasteco yellow vein virus (PHYVV) from the New World are included in the outgroup. The ToLCNDV isolated in this study and previously isolated ToLCNDV-[BACu-20] are shaded in black. ES indicates the ToLCNDV-ES strain, and the asterisk indicates ToLCNDV isolated from Southeast Asia and East Asia. The abbreviations used for the country of origin for the sequences are as follows: IN, India; PK, Pakistan; BD, Bangladesh; IR, Iran; ID, Indonesia; TA, Thailand; KH, Cambodia; LA, Laos; TW, Taiwan; IT, Italy; ES, Spain; DZ, Algeria; MA, Morocco; MX, Mexico. 


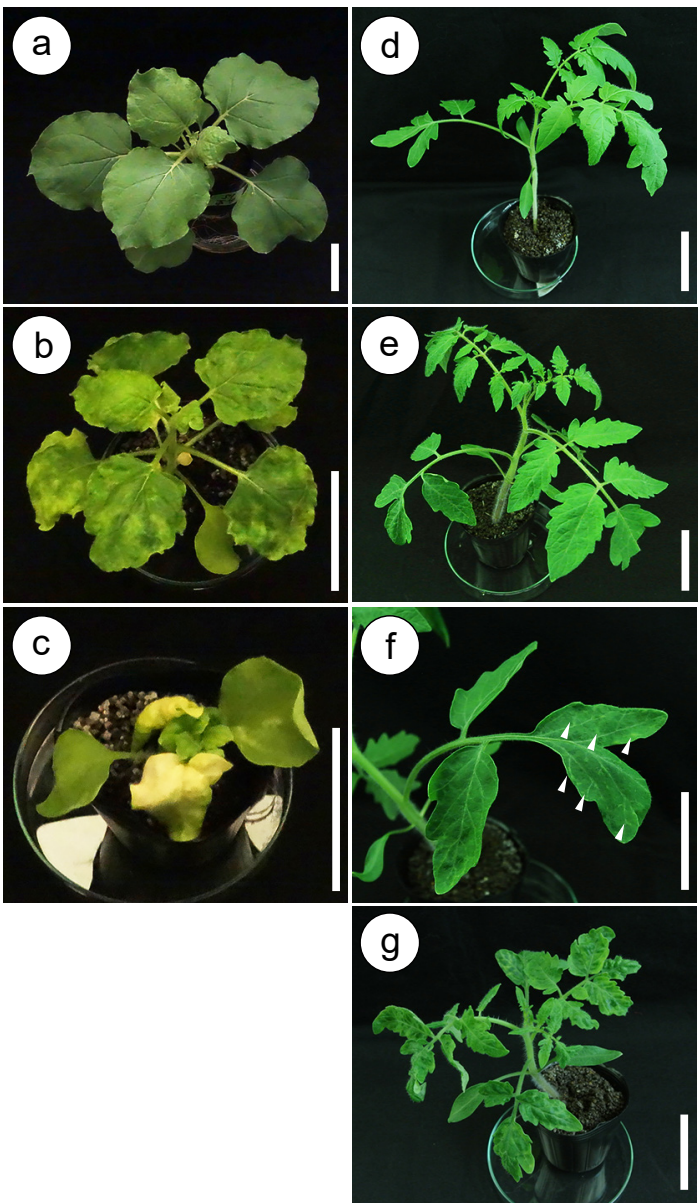

Fig. 4. N. benthamiana and tomato plants infected with tomato leaf curl New Delhi virus (ToLCNDV) via agroinfiltration. $N$. benthamiana plants of the (a) virus uninfected control, which was infected with (b) ToLCNDV-[ES-Alm-Cuc-16] and (c) ToLCNDV-[BACu-20]. Tomato plants of the (d) virus uninfected control; (e) the ToLCNDV-[ES-Alm-Cuc-16]-infected plant; (f) enlarged view of the ToLCNDV-[ES-Alm-Cuc-16]infected plant; and (g) the ToLCNDV-[BACu-20]-infected plant. The white arrowheads indicate slight vein yellowing. Pictures were taken of $N$. benthamiana at 30 days postinoculation and of tomato 20 days postinoculation. Bars indicate $6 \mathrm{~cm}$.

Table 2). All the symptomatic plants tested positive for ToLCNDV infection. These results demonstrated that the constructed clones of ToLCNDV isolates were infectious, and ToLCNDV-[BACu-20] had higher pathogenicity than ToLCNDV-[ES-Alm-Cuc-16] in $N$. benthamiana.

ToLCNDV-[ES-Alm-Cuc-16] and ToLCNDV$[\mathrm{BACu}-20]$ were agroinoculated to tomato plants using the colony inoculation procedure reported in our previous study (Koeda et al., 2017). Inoculation of empty pGreenII-p35S produced no virus symptoms (Fig. 4d; Table 2). For ToLCNDV-[ES-Alm-Cuc-16]-inoculated plants, 9/10 plants (Exp. 1) and 10/10 plants (Exp. 2) were infected by ToLCNDV (Table 2). Most of the infected plants were asymptomatic (Fig. 4e). However, 2/9 plants (Exp. 1) and 4/10 plants (Exp. 2) showed slight vein yellowing only in the lower leaves (Fig. 4f), whereas the newly developing upper leaves were asymptomatic. In contrast, for ToLCNDV-[BACu-20]inoculated plants, 10/10 plants (Exp. 1) and 9/9 plants (Exp.2) were infected by ToLCNDV, and almost all plants showed typical begomoviral symptoms with leaf yellowing and curling at $20 \mathrm{dpi}$ (Fig. 4g; Table 2). These results showed that ToLCNDV-[BACu-20] had higher pathogenicity than ToLCNDV-[ES-Alm-Cuc-16] in tomato.

Agroinfiltration of ToLCNDV isolates to cucurbit crops

Agroinfiltration of ToLCNDV was conducted on the abaxial sides of the cotyledons to cucumber, melon, and zucchini plants (Fig. 5; Table 3). Inoculation of empty pGreenII-p35S produced no virus symptoms in any of the inoculated samples. ToLCNDV-[ES-Alm-Cuc-16]inoculated cucumber plants showed yellowing and curling symptoms on leaves, and melon showed mainly heavy curling symptoms. ToLCNDV-[BACu-20]inoculated cucumber and melon plants had heavier yellowing, curling, and stunted symptoms compared to those of ToLCNDV-[ES-Alm-Cuc-16]-inoculated plants. Moreover, some of the ToLCNDV-[BACu-20]inoculated melon plants had pronounced necrosis of the leaves and stems, which led to plant death at $20 \mathrm{dpi}$. Plants with viral symptoms tested positive for ToLCNDV infection. For cucumber plants, inoculation was conducted at eight days after sowing the seeds in Exp. 1, and at five days after sowing the seeds in Exp. 2, which resulted in an earlier onset of symptoms and higher infectivity rate for Exp.2. It was assumed that the plant developmental stage critically affected the infectivity rate. In conclusion, ToLCNDV-[BACu-20] had higher pathogenicity than ToLCNDV-[ES-AlmCuc-16] in cucumber and melon plants.

Only a single zucchini plant out of twelve ToLCNDV-[ES-Alm-Cuc-16]-inoculated plants showed yellowing and curling symptoms, and none of the ToLCNDV-[BACu-20]-inoculated zucchini plants showed disease symptoms, which demonstrated that agroinfiltration is not effective in zucchini plants. Agroinfiltration was conducted on cotyledons using a needleless syringe, but the stiff and thick cotyledons of zucchini plants impeded the penetration of an inoculation buffer. Although we have also conducted agroinfiltration of petioles and stems using a needled syringe, 5 zucchini plants out of 27 ToLCNDV-[ES-Alm-Cuc-16]inoculated plants showed disease symptoms, and no significant increase in the incidence rate could be achieved by this modification.

\section{Colony inoculation procedure of ToLCNDV isolates in zucchini plants}

To screen for begomovirus-resistant accessions, asymptomatic resistance with successful infection must be distinguished from inoculation-escape. For that pur- 
Table 2. Agroinoculations of tomato leaf curl New Delhi virus (ToLCNDV) isolates to N. benthamiana and tomato plants.

\begin{tabular}{|c|c|c|c|c|c|c|}
\hline & \multirow{2}{*}{ Inoculation $^{2}$} & & \multicolumn{3}{|c|}{ Number of plants } & \multirow{2}{*}{$\begin{array}{l}\text { Symptom } \\
\text { severity }^{x}\end{array}$} \\
\hline & & & Inoculated & Infected $^{y}$ & With symptom & \\
\hline \multirow[t]{3}{*}{ N. benthamiana } & pGreenII-p35S & Exp. 1 & 15 & 0 & 0 & - \\
\hline & ToLCNDV-[ES-Alm-Cuc-16] & Exp. 1 & 15 & 15 & 15 & +++ \\
\hline & ToLCNDV-[BACu-20] & Exp. 1 & 15 & 15 & 15 & ++++ \\
\hline \multirow[t]{6}{*}{ Tomato } & pGreenII-p35S & Exp. 1 & 10 & 0 & 0 & - \\
\hline & & Exp. 2 & 10 & 0 & 0 & - \\
\hline & ToLCNDV-[ES-Alm-Cuc-16] & Exp. 1 & 10 & 9 & 2 & $-*$ \\
\hline & & Exp. 2 & 10 & 10 & 4 & $-*$ \\
\hline & ToLCNDV-[BACu-20] & Exp. 1 & 10 & 10 & 9 & +++ \\
\hline & & Exp. 2 & 9 & 9 & 9 & +++ \\
\hline
\end{tabular}

z Exp. 1 and Exp. 2 were conducted in different dates.

y Virus infection was detected by PCR.

x -: no symptom, $-*$ : slight vein yellowing, +++: severe leaf curling and yellowing, leaf area reduction, stunting, ++++: severe leaf curling and yellowing, leaf area reduction, severe stunting, chlorosis. Symptom survey was conducted at 30 dpi for $N$. benthamiana and at 20 dpi for tomato.

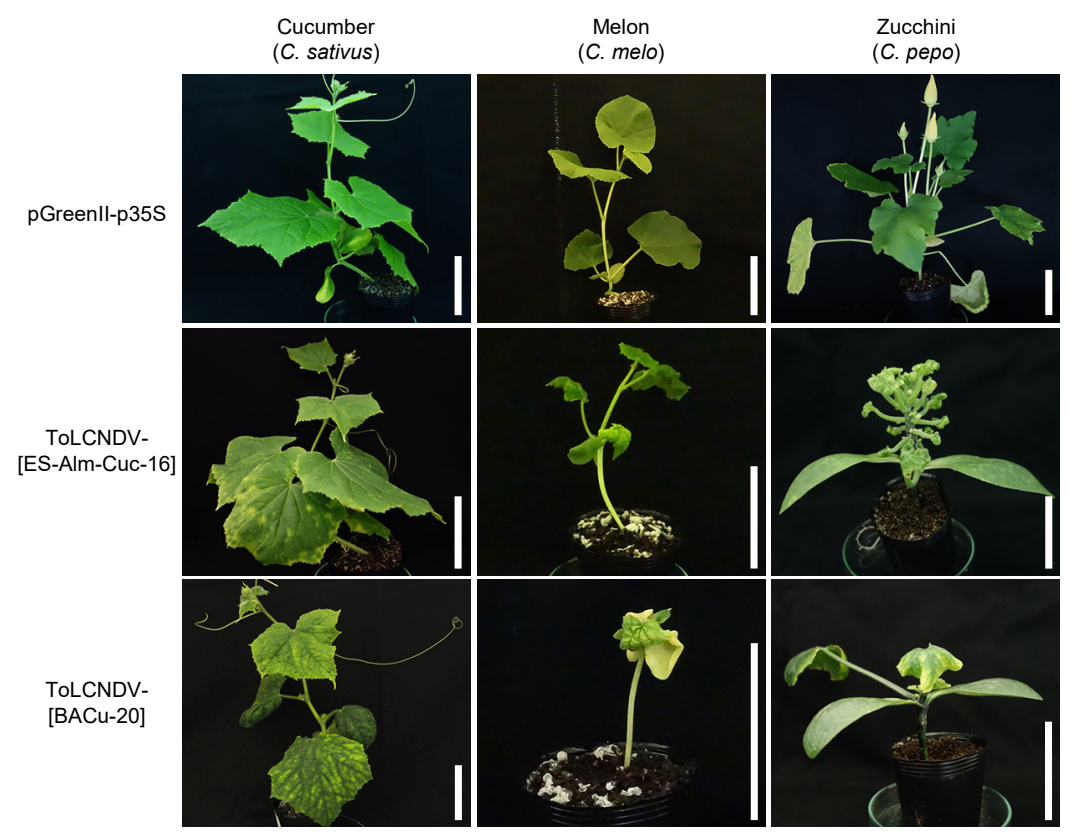

Fig. 5. Cucumber, melon, and zucchini plants infected by tomato leaf curl New Delhi virus (ToLCNDV) via agroinoculation. Cucumber and melon plants were inoculated by agroinfiltration of the cotyledons. Zucchini plants were agroinoculated via the colony inoculation procedure. Pictures were taken at 30 days postinoculation. Bars indicate $6 \mathrm{~cm}$.

pose, the inoculation efficiency needs to be close to $100 \%$. To achieve this goal, a colony inoculation procedure was conducted (Fig. 5; Table 4). ToLCNDV-[ESAlm-Cuc-16]-inoculated zucchini plants started to show symptoms at $5 \mathrm{dpi}$, and all the inoculated plants showed heavy yellowing, curling, and stunted symptoms at 30 dpi. ToLCNDV-[BACu-20]-inoculated zucchini plants started to show symptoms at $6 \mathrm{dpi}$, and all the inoculated plants developed only two true leaves with no additional leaf development until $30 \mathrm{dpi}$. Plants with viral symptoms tested positive for ToLCNDV infection. These results showed that the colony inoculation procedure was highly effective for zucchini plants, and again
ToLCNDV-[BACu-20] showed higher pathogenicity than ToLCNDV-[ES-Alm-Cuc-16].

\section{Discussion}

ToLCNDV was first identified in India, and its distribution has been documented across the Indian subcontinent, Southeast Asia, East Asia, the Middle East, and the Mediterranean Basin. This pathogen infects at least 44 dicotyledonous plant species, including weeds and economically important vegetable and ornamental species (EPPO, 2020; Zaidi et al., 2017). Several reports have indicated that disease caused by ToLCNDV is becoming a serious threat to cucurbit 
Table 3. Agroinfiltrations of tomato leaf curl New Delhi virus (ToLCNDV) isolates to cucumber and melon plants.

\begin{tabular}{|c|c|c|c|c|c|c|}
\hline & \multirow{2}{*}{ Inoculation $^{z}$} & & \multicolumn{3}{|c|}{ Number of plants } & \multirow{2}{*}{$\begin{array}{l}\text { Symptom } \\
\text { severity }^{x}\end{array}$} \\
\hline & & & Inoculated & Infected ${ }^{y}$ & With symptom & \\
\hline \multirow[t]{6}{*}{ Cucumber } & pGreenII-p35S & Exp. 1 & 15 & 0 & 0 & - \\
\hline & & Exp. 2 & 15 & 0 & 0 & - \\
\hline & ToLCNDV-[ES-Alm-Cuc-16] & Exp. 1 & 15 & 13 & 13 & + \\
\hline & & Exp. 2 & 13 & 13 & 13 & + \\
\hline & ToLCNDV-[BACu-20] & Exp. 1 & 15 & 14 & 14 & ++ \\
\hline & & Exp. 2 & 14 & 14 & 14 & ++ \\
\hline \multirow[t]{6}{*}{ Melon } & pGreenII-p35S & Exp. 1 & 15 & 0 & 0 & - \\
\hline & & Exp. 2 & 13 & 0 & 0 & - \\
\hline & ToLCNDV-[ES-Alm-Cuc-16] & Exp. 1 & 15 & 15 & 15 & +++ \\
\hline & & Exp. 2 & 13 & 13 & 13 & +++ \\
\hline & ToLCNDV-[BACu-20] & Exp. 1 & 15 & 15 & 15 & ++++ \\
\hline & & Exp. 2 & 13 & 13 & 13 & ++++ \\
\hline
\end{tabular}

${ }^{z}$ Exp. 1 and Exp. 2 were conducted in different dates.

y Virus infection was detected by PCR.

$x$-: no symptom, +: leaf curling and yellowing, ++: severe leaf curling and yellowing, +++ : severe leaf curling, leaf yellowing, leaf area reduction, and stunting, ++++: severe leaf curling, leaf yellowing, leaf area reduction, severe stunting, and chlorosis. Symptom survey was conducted on 30 dpi.

Table 4. Agroinoculations of tomato leaf curl New Delhi virus (ToLCNDV) isolates to zucchini plants.

\begin{tabular}{|c|c|c|c|c|c|c|}
\hline & \multirow{2}{*}{ Inoculation $^{2}$} & & \multicolumn{3}{|c|}{ Number of plants } & \multirow{2}{*}{$\begin{array}{l}\text { Symptom } \\
\text { severity }^{\mathrm{x}}\end{array}$} \\
\hline & & & Inoculated & Infected ${ }^{y}$ & With symptom & \\
\hline \multirow[t]{6}{*}{ Zucchini } & pGreenII-p35S & Exp. 1 & 15 & 0 & 0 & - \\
\hline & & Exp. 2 & 15 & 0 & 0 & - \\
\hline & ToLCNDV-[ES-Alm-Cuc-16] & Exp. 1 & 15 & 15 & 15 & +++ \\
\hline & & Exp. 2 & 15 & 15 & 15 & +++ \\
\hline & ToLCNDV-[BACu-20] & Exp. 1 & 15 & 15 & 15 & ++++ \\
\hline & & Exp. 2 & 15 & 15 & 15 & ++++ \\
\hline
\end{tabular}

${ }^{z}$ Exp. 1 and Exp. 2 were conducted in different dates.

y Virus infection was detected by PCR.

$\mathrm{x}-$ : no symptom, +++: severe leaf curling, leaf yellowing, leaf area reduction, and stunting, ++++: severe stunting without leaf development. Symptom survey was conducted on 30 dpi.

crops in these regions. ToLCNDV was found to cause a yield loss of more than $60 \%$, with a maximum disease incidence of $100 \%$ for chayote (Sechium edule) in India (Nagendran et al., 2017). Up to $22 \%$ of zucchini crops cultivated in the greenhouses at Almeria were affected by ToLCNDV (Crespo et al., 2020), and melon yield losses were approximately $20 \%$ in open fields in central Spain (Sáez et al., 2017). In the Campania region of southern Italy, the incidence of this disease ranged from $80 \%$ to $100 \%$ of C. moschata plants (Parrella et al., 2017). In this study, analysis of the phylogenetic relationship among ToLCNDV isolates from Spain and Indonesia revealed that ToLCNDV-[ES-Alm-Cuc-16] from Spain and ToLCNDV-[BACu-20] from Indonesia are representative isolates from the Mediterranean Basin and Southeast Asia or East Asia that are genetically distant from each other (Figs. 3 and S1). Infectious clones for these isolates were prepared, and agroinoculation was conducted to compare the pathogenicity.

High infectivity rates were achieved in $N$. benthamiana, cucumber, and melon plants by using agroinfiltration, and for tomato and zucchini plants by using the colony inoculation procedure (Tables 2, 3, and 4). Cucurbit plants agroinoculated with ToLCNDV[ES-Alm-Cuc-16], especially melon and zucchini plants, showed more severe symptoms compared to those of the field-cultivated plants at Almeria, Spain (Figs. 1 and 5), which was probably because agroinoculation was conducted during the small seedling stage with cotyledons before the development of true leaves. ToLCNDV-[BACu-20] caused consistently more severe disease symptoms compared to those of ToLCNDV[ES-Alm-Cuc-16] in all the tested plant species. Fortes et al. (2016) compared the pathogenicity between ToLCNDV-ES and ToLCNDV-[IN-ND-Svr-92] (DNAA: U15015, DNA-B: U15017) from India, and showed that ToLCNDV-[IN-ND-Svr-92] has higher pathogenic- 
ity in tomato and zucchini plants. In the present study, ToLCNDV-[BACu-20] from Indonesia (Southeast Asia), which was genetically distant from ToLCNDV[IN-ND-Svr-92] (DNA-A: U15015) (Figs. 3 and S1), also showed higher pathogenicity compared to ToLCNDV-ES. These results together indicated that although the pathogenicity of ToLCNDV-ES is high enough to cause significant economic damage in horticultural production in the Mediterranean Basin, Asian isolates have an even higher pathogenicity.

There are contradicting reports on the symptoms that are induced by ToLCNDV-ES. Fortes et al. (2016) reported asymptomatic infection of ToLCNDV-ES in tomato plants, whereas Ruiz et al. (2017) reported chlorotic mosaic and curling symptoms in agroinoculation-induced tomato plants. The present study also demonstrated the asymptomatic infection of ToLCNDV-ES in most plants, which coincides with the report by Fortes et al. (2016) (Fig. 4e; Table 2). A minor difference from their report was that a few ToLCNDV-ES-infected plants showed slight vein yellowing only in the lower leaves (Fig. 4f). In contrast to ToLCNDV-ES, ToLCNDV-[BACu-20] infected and caused typical begomoviral symptoms (Fig. 4; Table 2). Previous diagnosis that detected begomovirus in Solanaceae crops (tomato, pepper, eggplant, and tobacco) in Aceh province, Indonesia, indicated that all diagnosed samples were negative for ToLCNDV infection and were only positive for other begomovirus species, such as pepper yellow leaf curl Indonesia virus, pepper yellow leaf curl Aceh virus, tomato yellow leaf curl Kanchanaburi virus (TYLCKaV), and ageratum yellow vein virus (Kesumawati et al., 2019, 2020; Koeda et al., 2016). It was reported that ToLCNDV-[OM] (DNA-A: GU180095) isolated from oriental melon (C. melo) in Taiwan infected cucurbit crops, but not tomato plants, by mechanical inoculation (Chang et al., 2010). Wilisiani et al. (2019) also reported that ToLCNDV[ID-YG-Mel-15] (DNA-A: LC335722), which is a recombinant begomovirus between ToLCNDV and squash leaf curl China virus, infected melon plants with symptom induction, whereas tomato plants were uninfected by biolistic inoculation. In contrast, ToLCNDV diagnosis using samples collected from different regions of Thailand revealed that the main host for ToLCNDV was cucurbit crops, although several tomato and pepper samples were also positive for infection (Charoenvilaisiri et al., 2020). Our phylogenetic analysis showed that ToLCNDV-[BACu-20] is closely related to ToLCNDV-[OM] and ToLCNDV-[IDYG-Mel-15] (Figs. 3 and S1). Sequence differences scattered in DNA-A or DNA-B or the difference between inoculation methods may affect the pathogenicity against tomato plants. Further comparisons among Southeast and East Asia ToLCNDV isolates may clarify which genomic region is responsible for these infectivity differences.
Global dissemination of a monopartite begomovirus, TYLCV, began in the 1980s after the emergence of the TYLCV-Mld and TYLCV-IL strains. Now, TYLCV is recognized as one of the world's most devastating pathogens in tomato plants (Mabvakure et al., 2016). In Japan, the TYLCV-Mld strain was first isolated in Shizuoka and Aichi prefectures in 1996 (Kato et al., 1998), and the TYLCV-IL strain was isolated in the Kyushu district in 1996 (Onuki et al., 2004); it is assumed to have invaded from Israel and Spain (Mabvakure et al., 2016). Among the 424 begomovirus species reported in ICTV, ToLCNDV possibly carries the highest risk of dispersal to Japan among begomovirus species. Considering the past occurrence of TYLCV, adequate precautions need to be taken against ToLCNDV-ES expansion from the Mediterranean Basin. In addition, although there are contradictory reports on the seed transmission of TYLCV (Kil et al., 2016; Pérez-Padilla et al., 2020), this unique transmission characteristic of TYLCV may contribute to global dissemination. Because seed transmission has also been reported for ToLCNDV in zucchini plants (Kil et al., 2020), and seed production of many cucurbit crops that are sold in the Japanese market is conducted in Southeast Asian countries, there is also a risk of invasion of Southeast Asian ToLCNDV isolates into Japan.

In the Japanese commercial tomato seed market, introgressions of $T y-1, T y-2, T y-3$, or $T y-3 a$ have been the major focus of breeding programs (Saito et al., 2008); currently, TYLCV-Mld and TYLCV-IL are well controlled, mainly by $T y-3$ and $T y-3 a$, both of which are allelic to $T y-1$, which is reported to be effective against ToLCNDV-ES (Fortes et al., 2016), whereas Ty- 1 and $T y-3$ are reported to be only partially effective against the ToLCNDV isolate from India (Prasanna et al., 2015). Moreover, we have previously reported that $T y-2$ and $T y-3 a$-conferred begomovirus resistance in tomato is inadequate against the TYLCKaV isolate from Indonesia (Koeda et al., 2020). These reports strongly suggest the importance of evaluating the effectiveness of pyramiding multiple $T y$ genes for the Japanese tomato seed market in preparation for the future invasion of multiple begomoviruses with stronger pathogenicity, including ToLCNDV. Although several studies have reported the resistance of melon, C. moschata, and L. cylindrica accessions to ToLCNDV (Islam et al., 2010; López et al., 2015; Sáez et al., 2016), resistance to begomovirus infection is much less advanced in cucurbit crops compared to that of tomato. As yet, there are no commercial cultivars carrying resistance to begomovirus infection. Since the expansion of cucurbit-infecting begomovirus ToLCNDV into Japan will result in devastating economic loss, breeding of ToLCNDV resistance is important for horticultural production in European and Asian countries, as well as in Japan.

Most of the virus resistance genes in plants either 
prevent or restrict viral replication to the cells targeted by the virus to enter the host (Kang et al., 2005). However, the resistance against begomovirus in well-studied tomatoes is different, and the TYLCV resistance conferred by $T y-1 / T y-3, T y-2$, and ty-5 is a level of virus tolerance rather than immunity (Lapidot et al., 2015; Verlaan et al., 2013; Yamaguchi et al., 2018). Plants carrying these resistance genes and challenged by the virus still show low levels of viral replication and systemic spread, but with mild or no visual symptoms. Considering these reports, we propose to select resistant resources from the cucurbit germplasm in a step-bystep manner. For the initial screening of resistant candidates, the agroinoculation method reported in this study is an effective tool for saving time and labor to inoculate and evaluate a large number of plants. However, some of the resistant candidates selected by agroinoculation may be false resistant, possessing an incompatibility with the used agrobacterium. To further select for resistance against begomovirus in the second screening, we recommend using the graft-inoculation method with resistant candidates from the initial screening (Koeda et al., 2018). Graft-inoculation of begomovirus requires more time and labor compared to agroinoculation, but it helps avoid the effect of incompatibility with agrobacterium. This step-by-step screening method will ensure the accurate selection of resistant sources. In addition to the fact that mild or no visual symptoms are observed in resistant candidates, it is also important to show that begomoviral DNA accumulation in the resistant candidates is restricted compared to the susceptible control by viral DNA quantification using quantitative PCR (Koeda et al., 2020).

All previously reported ToLCNDV-resistant accessions were screened and evaluated by mechanical transmission or whitefly-mediated inoculation (Islam et al., 2010; López et al., 2015; Sáez et al., 2016), and several studies have genetically mapped the quantitative trait loci responsible for ToLCNDV resistance in melon and C. moschata (Sáez et al., 2016, 2020). In this study, highly effective agroinoculation methods of ToLCNDV isolates from the Mediterranean Basin and Southeast Asia were established for tomato and cucurbit crops, and these offer another approach for the evaluation of begomovirus resistance as a genetic resource.

\section{Acknowledgements}

We would like to thank Gabriel, Miguel, and Saiichi (Takii Spain) for field work at Almeria, Spain, and thank Hayato Shiragane (Takii Japan) for supporting DNA preparation and RCA.

\section{Literature Cited}

Agrama, H. A. and J. W. Scott. 2006. Quantitative trait loci for tomato yellow leaf curl virus and tomato mottle virus resistance in tomato. J. Amer. Soc. Hort. Sci. 131: 267-272.

Anbinder, I., M. Reuveni, R. Azari, I. Paran, S. Nahon, H.
Shlomo, L. Chen, M. Lapidot and I. Levin. 2009. Molecular dissection of Tomato leaf curl virus resistance in tomato line TY172 derived from Solanum peruvianum. Theor. Appl. Genet. 119: 519-530.

Briddon, R. W. and P. G. Markham. 1994. Universal primers for the PCR amplification of dicot Infecting geminiviruses. Mol. Biotechnol. 1: 202-205.

Brown, J. K., F. M. Zerbini, J. Navas-Castillo, E. Moriones, R. Ramos-Sobrinho, J. C. F. Silva, E. Fiallo-Olivé, R. W. Briddon, C. Hernández-Zepeda, A. Idris, V. G. Malathi, D. P. Martin, R. Rivera-Bustamante, S. Ueda and A. Varsani. 2015. Revision of Begomovirus taxonomy based on pairwise sequence comparisons. Arch. Virol. 160: 1593-1619.

Chang, H., H. Ku, W. Tsai, R. Chien and F. Jan. 2010. Identification and characterization of a mechanical transmissible begomovirus causing leaf curl on oriental melon. Eur. J. Plant Pathol. 127: 219-228.

Charoenvilaisiri, S., C. Seepiban, N. Phironrit, B. Phuangrat, K. Yoohat, R. Deeto, O. Chatchawankanphanich and O. Gajanandana. 2020. Occurrence and distribution of begomoviruses infecting tomatoes, peppers and cucurbits in Thailand. Crop Prot. 127: 104948.

Cohen, S. and F. E. Nitzany. 1960. Curly top virus of tomatoes: Its identification and mode of transmission. Report No. 311 of the Israeli Plant Protection and Inspection Services (In Hebrew).

Cohen, S. and F. E. Nitzany. 1966. Transmission and host range of tomato yellow leaf curl virus. Phytopathology 56: 1127 1131.

Crespo, O., C. Robles, L. Ruiz and D. Janssen. 2020. Antagonism of Cucumber green mottle mosaic virus against Tomato leaf curl New Delhi virus in zucchini and cucumber. Ann. Appl. Biol. 176: 147-157.

Edgar, R. C. 2004. MUSCLE: multiple sequence alignment with high accuracy and high throughput. Nucleic Acids Res. 32: 1792-1797.

European and Mediterranean Plant Protection Organization (EPPO). 2020. <https://www.eppo.int/ACTIVITIES/plant quarantine/alert list_viruses/tomato leafcurl_newdelhi> (Accessed: November 22, 2020)

Fortes, I. M., S. Sánchez-Campos, E. Fiallo-Olivé, J. A. DíazPendón, J. Navas-Castillo and E. Moriones. 2016. A novel strain of tomato leaf curl New Delhi virus has spread to the Mediterranean basin. Viruses 8: 307. DOI: 10.3390/ v8110307.

Hanley-Bowdoin, L., E. R. Bejarano, D. Robertson and S. Mansoor. 2013. Geminiviruses: masters at redirecting and reprogramming plant processes. Nat. Rev. Microbiol. 11: 777-788.

Hussain, M., S. Manssor, S. Iram, Y. Zafar and R. W. Briddon. 2004. First report of Tomato leaf curl New Delhi virus affecting chilli pepper in Pakistan. Plant Pathology 53: 794.

Hutton, S. F. and J. W. Scott. 2014. Ty-6, a major begomovirus resistance gene located on chromosome 10. Rept. Tomato Genet. Coop. 64: 14-18.

Islam, S., A. D. Mushi, B. Mandal, R. Kumar and T. K. Behera. 2010. Genetics of resistance in Luffa cylindrica Roem. against Tomato leaf curl New Delhi virus. Euphytica 174: 83-89.

Ito, T., P. Sharma, K. Kittipakorn and M. Ikegami. 2008. Complete nucleotide sequence of a new isolate of tomato leaf curl New Delhi virus infecting cucumber, bottle gourd and muskmelon in Thailand. Arch. Virol. 153: 611-613.

Ji, Y., J. W. Scott and D. J. Schuster. 2009a. Toward fine mapping of the Tomato yellow leaf curl virus resistance gene Ty-2 on 
chromosome 11 of tomato. HortScience 44: 614-618.

Ji, Y., J. W. Scott, D. J. Schuster and D. P. Maxwell. 2009b. Molecular mapping of $T y-4$, a new tomato yellow leaf curl virus resistance locus on chromosome 3 of tomato. J. Amer. Soc. Hort. Sci. 134: 281-288.

Juárez, M., M. P. Rabadán, L. D. Martínez, M. Tayahi, A. Grande-Pérez and P. Gómez. 2019. Natural hosts and genetic diversity of the emerging tomato leaf curl New Delhi virus in Spain. Front. Microbiol. 2019: 140. DOI: 10.3389/ fmicb.2019.00140.

Juárez, M., R. Tovar, E. Fiallo-Olivé, M. A. Aranda, B. Gosálvez, P. Castillo, E. Moriones and J. Navas-Castillo. 2014. First detection of Tomato leaf curl New Delhi virus infecting zucchini in Spain. Plant Dis. 98: 857.

Kang, B. C., I. Yeam and M. M. Jahn. 2005. Genetics of plant virus resistance. Annu. Rev. Phytopathol. 43: 581-621.

Kato, K., M. Onuki, S. Fuji and K. Hanada. 1998. The first occurrence of tomato leaf curl virus in tomato (Lycopersicon esculentum Mill.) in Japan. Ann. Phytopathol. Soc. Jpn. 64: $552-559$.

Kesumawati, E., S. Okabe, K. Homma, I. Fujiwara, S. Zakaria, S. Kanzaki and S. Koeda. 2019. Pepper yellow leaf curl Aceh virus: a novel bipartite begomovirus isolated from chili pepper, tomato, and tobacco plants in Indonesia. Arch. Virol. 164: 2379-2383.

Kesumawati, E., S. Okabe, M. Khalil, G. Alfan, P. Bahagia, N. Pohan, S. Zakaria and S. Koeda. 2020. Molecular characterization of begomoviruses associated with yellow leaf curl disease in Solanaceae and Cucurbitaceae crops from Northern Sumatra, Indonesia. Hort. J. 89: 410-416.

Kheireddine, A., A. Sifres, C. Sáez, B. Picó and C. López. 2019. First report of Tomato leaf curl New Delhi virus infecting cucurbit plants in Algeria. Plant Dis. 103: 3291.

Kil, E.-J., S. Kim, Y.-J. Lee, H.-S. Byun, J. Park, H. Seo, C.-S. Kim, J.-K. Shim, J.-H. Lee, J.-K. Kim, K.-Y. Lee, H.-S. Choi and S. Lee. 2016. Tomato yellow leaf curl virus (TYLCVIL): a seed-transmissible geminivirus in tomatoes. Sci. Rep. 6: 19013. DOI: 10.1038/srep19013.

Kil, E.-J., T. T. B. Vo, C. Fadhila, P. T. Ho, A. Lal, E. Troiano, G. Parrella and S. Lee. 2020. Seed transmission of tomato leaf curl New Delhi virus from zucchini squash in Italy. PlantsBasel 9: 563. DOI: 10.3390/plants9050563.

Koeda, S. and I. Fujiwara. 2019. A simple DNA extraction method for begomovirus detection and genotyping of host plants. Trop. Agr. Dev. 63: 34-37.

Koeda, S., I. Fujiwara, Y. Oka, E. Kesumawati, S. Zakaria and S. Kanzaki. 2020. $T y-2$ and $T y-3 a$ conferred resistance are insufficient against tomato yellow leaf curl Kanchanaburi virus from Southeast Asia in single or mixed infections of tomato. Plant Dis. 104: 3221-3229.

Koeda, S., K. Homma, Y. Tanaka, E. Kesumawati, S. Zakaria and S. Kanzaki. 2017. Highly efficient agroinoculation method for tomato plants with Tomato yellow leaf curl Kanchanaburi virus. Hort. J. 86: 479-486.

Koeda, S., K. Homma, Y. Tanaka, D. Onizaki, E. Kesumawati, S. Zakaria and S. Kanzaki. 2018. Inoculation of capsicums with Pepper yellow leaf curl Indonesia virus by combining agroinoculation and grafting. Hort. J. 87: 364-371.

Koeda, S., E. Kesumawati, Y. Tanaka, M. Hosokawa, M. Doi and A. Kitajima. 2016. Mixed infection of begomoviruses on pepper plants at northern Sumatra, Indonesia. Trop. Agric. Dev. 60: 59-64.

Koeda, S., R. Takisawa, T. Nabeshima, Y. Tanaka and A. Kitajima. 2015. Production of Tomato yellow leaf curl virus free parthenocarpic tomato plants by leaf primordia-free shoot apical meristem culture combined with in vitro grafting. Hort. J. 84: 327-333.

Kumar, S., G. Stecher and K. Tamura. 2016. MEGA7: molecular evolutionary genetics analysis version 7.0 for bigger datasets. Mol. Biol. Evol. 33: 1870-1874.

Lapidot, M., U. Karniel, D. Gelbart, D. Fogel, D. Evenor, Y. Kutsher, Z. Makhbash, S. Nahon, H. Shlomo, L. Chen, M. Reuveni and I. Levin. 2015. A novel route controlling begomovirus resistance by the messenger RNA surveillance factor Pelota. PLoS Genet. 11: e1005538. DOI: 10.1371/ journal.pgen.1005538.

López, C., M. Ferriol and M. B. Picó. 2015. Mechanical transmission of Tomato leaf curl New Delhi virus to cucurbit germplasm: selection of tolerance sources in Cucumis melo. Euphytica 204: 679-691.

Mabvakure, B., D. P. Martin, S. Kraberger, L. Cloete, S. van Brunschot, A. D. G. Geering, J. E. Thomas, K. Bananej, J. M. Lett, P. Lefeuvre, A. Varsani and G. W. Harkins. 2016. Ongoing geographical spread of Tomato yellow leaf curl virus. Virology 498: 257-264.

Maruthi, M. N., A. R. Rekha, A. Cork, J. Colvin, S. N. Alam and K. A. Kader. 2005. First report of Tomato leaf curl New Delhi virus infecting tomato in Bangladesh. Plant Dis. 89: 1011.

Mizutani, T., B. S. Daryono, M. Ikegami and K. T. Natsuaki. 2011. First report of Tomato leaf curl New Delhi virus infecting cucumber central Java, Indonesia. Plant Dis. 95: 1485.

Mnari-Hattab, M., S. Zammouri, M. S. Belkadhi, D. Bellon Doña, E. ben Nahia and M. R. Hajlaoui. 2015. First report of Tomato leaf curl New Delhi virus infecting cucurbits in Tunisia. New Dis. Rep. 31: 21.

Moriones, E., S. Praveen and S. Chakraborty. 2017. Tomato leaf curl New Delhi virus: an emerging virus complex threatening vegetable and fiber crops. Viruses 9: 264. DOI: 10.3390/ v9100264.

Muhire, B. M., A. Varsani and D. P. Martin. 2014. SDT: a virus classification tool based on pairwise sequence alignment and identity calculation. PLoS One 9: e108277. DOI: 10.1371/ journal.pone.0108277.

Nagendran, K., S. Mohankumar, P. M. Faisal, B. Bagewadi and G. Karthikeyan. 2017. Molecular evidence for the occurrence of the tomato leaf curl New Delhi virus on chayote (Sechium edule) in southern India. Virus Dis. 28: 425-429.

Navas-Castillo, J., E. Fiallo-Olivé and S. Sánchez-Campos. 2011. Emerging virus diseases transmitted by whiteflies. Annu. Rev. Phytopathol. 49: 219-248.

Onuki, M., T. Ogawa, K. Uchikawa, K. Kato and K. Hanada. 2004. Molecular characterization and strain-specific detection of the tomato yellow leaf curl virus occurring in Kyushu, Japan. Bull. Natl. Agric. Res. Center Kyushu Okinawa Reg. 44: 55-77 (In Japanese).

Orfanidou, C. G., L. Malandraki, D. Beris, O. Kektsidou, N. Vassilakos, C. Varveri, N. I. Katis and V. I. Maliogka. 2019. First report of tomato lead curl New Delhi virus in zucchini crops in Greece. J. Plant Pathol. 101: 799.

Padidam, M., R. N. Beachy and C. M. Fauquet. 1995. Tomato leaf curl geminivirus from India has a bipartite genome and coat protein is not essential for infectivity. J. Gen. Virol. 76: 25-35.

Palumbo, J. C., A. R. Horowitz and N. Prabhaker. 2001. Insecticidal control and resistance management for Bemisia tabaci. Crop Prot. 20: 739-765.

Panno, S., G. lacono, M. Davino, S. Marchione, V. Zappardo, P. Bella, L. Tomassoli, G. P. Accotto and S. Davino. 2016. First report of tomato leaf curl New Delhi virus affecting zucchini 
squash in an important horticultural area of southern Italy. New Dis. Rep. 33: 6.

Parrella, G., E. Troiano, G. Formisano, G. P. Accotto and M. Giorgini. 2017. First report of Tomato leaf curl New Delhi virus associated with severe mosaic of pumpkin in Italy. Plant Dis. 102: 459.

Pérez-Padilla, V., I. M. Fortes, B. Romero-Rodríguez, M. ArroyoMateos, A. G. Castillo, C. Moyano, L. De León and E. Moriones. 2020. Revisiting seed transmission of the type strain of Tomato yellow leaf curl virus in tomato plants. Phytopathology 110: 121-129.

Phaneendra, C., K. R. S. S. Rao, R. K. Jain and B. Mandal. 2012. Tomato leaf curl New Delhi virus is associated with pumpkin leaf curl: a new disease in Northern India. Ind. J. Virol. 23: $42-45$.

Prasanna, H. C., D. P. Sinha, G. K. Rai, R. Krishna, S. P. Kashyap, N. K. Singh, M. Singh and V. G. Malathi. 2015. Pyramiding $T y-2$ and $T y-3$ genes for resistance to monopartite and bipartite tomato leaf curl viruses of India. Plant Pathol. 64: 256-264.

Rojas, M. R., M. A. Macedo, M. R. Maliano, M. Soto-Aguilar, J. O. Souza, R. W. Briddon, L. Kenyon, R. F. Rivera Bustamante, F. M. Zerbini, S. Adkins, J. P. Legg, A. Kvarnheden, W. M. Wintermantel, M. R. Sudarshana, M. Peterschmitt, M. Lapidot, D. P. Martin, E. Moriones, A. K. Inoue-Nagata and R. L. Gilbertson. 2018. World management of geminiviruses. Annu. Rev. Phytopathol. 56: 637677.

Ruiz, M. L., A. Simón, L. Velasco, M. C. García and D. Janssen. 2015. First report of Tomato leaf curl New Delhi virus infecting tomato in Spain. Plant Dis. 99: 894.

Ruiz, L., A. Simon, L. Velasco and D. Janssen. 2017. Biological characterization of Tomato leaf curl New Delhi virus from Spain. Plant Pathol. 66: 376-382.

Sáez, C., C. Esteras, C. Martínez, M. Ferriol, N. P. S. Dhillon, C. López and B. Picó. 2017. Resistance to tomato leaf curl New Delhi virus in melon is controlled by a major QTL located in chromosome 11. Plant Cell Rep. 36: 1571-1584.

Sáez, C., C. Matinez, M. Ferriol, S. Manzano, L. Velasco, M. Jamilena, C. López and B. Picó. 2016. Resistance to tomato leaf curl New Delhi virus in Cucurbita spp. Ann. Appl. Biol. 169: 91-105.

Sáez, C., C. Matinez, J. Montero-Pau, C. Esteras, A. Sifres, J. Blanca, M. Ferriol, C. López and B. Picó. 2020. A major QTL located in chromosome 8 of Cucurbita moschata is responsible for resistance to Tomato leaf curl New Delhi virus. Front. Plant Sci. 11: 207. DOI: 10.3389/fpls.2020. 00207.

Saito, A., T. Saito, H. Matsunaga and H. Yamada. 2008. Evaluation of commercial cultivars resistant to tomato yellow leaf curl virus using quantitative real-time PCR in tomato
(Solanum lycopersicum). Hort. Res. (Japan) 7: 107 (In Japanese).

Scholthof, K. B. G., S. Adkins, H. Czosnek, P. Palukaitis, E. Jacquot, T. Hohn, B. Hohn, K. Saunders, T. Candresse, P. Ahlquist, C. Hemenway and G. D. Foster. 2011. Top 10 plant viruses in molecular plant pathology. Mol. Plant Pathol. 12: 938-954.

Sifres, A., C. Sáez, M. Ferriol, E. A. Selmani, J. Riado, B. Picó and C. López. 2018. First report of Tomato leaf curl New Delhi virus infecting zucchini in Morocco. Plant Dis. 102: 1045.

Sohrab, S. S., B. Mandal, R. P. Pant and A. Verma. 2003. First report of assosciation of tomato leaf curl virus-New Delhi with yellow mosaic disease of Luffa cylindrica in India. Plant Dis. 87: 1148.

Valera, D. L., L. J. Belmonte, F. D. Molina-Aiz and A. López. 2016. Greenhouse agriculture in Almeria: A comprehensive techno-economic analysis. Cajamar Caja Rural, Almería, Spain.

Verlaan, M. G., S. F. Hutton, R. M. Ibrahem, R. Kormelink, R. G. F. Visser, J. W. Scott, J. D. Edwards and Y. Bai. 2013. The Tomato yellow leaf curl virus resistance genes $T y-1$ and $T y-3$ are allelic and code for DFDGD-class RNA-dependent RNA polymerases. PLoS Genet. 9: e1003399. DOI: 10.1371/journal.pgen.1003399.

Wilisiani, F., T. Mashiko, W. Wang, T. Suzuki, S. Hartono, Y. Neriya, H. Nishigawa and T. Natsuaki. 2019. New recombinant of tomato leaf curl New Delhi virus infecting melon in Indonesia. J. Gen. Plant Pathol. 85: 306-310.

Yamaguchi, H., J. Ohnishi, A. Saito, A. Ohyama, T. Nunome, K. Miyatake and H. Fukuoka. 2018. An NB-LRR gene, TYNBS1, is responsible for resistance mediated by the $T y-2$ Begomovirus resistance locus of tomato. Theor. Appl. Genet. 131: 1345-1362.

Yan, Z., A. Pérez-de-Castro, M. J. Díez, S. F. Hutton, R. G. F. Visser, A. A. Wolters, Y. Bai and J. Li. 2018. Resistance to tomato yellow leaf curl virus in tomato germplasm. Front. Plant Sci. 9: 1198.

Yazdani-Khameneh, S., S. Aboutorabi, M. Shoori, A. Aghazadeh, P. Jahanshahi, A. Golnaraghi and M. Maleki. 2016. Natural occurrence of Tomato leaf curl New Delhi virus in Iranian cucurbit crops. Plant Pathol. J. 32: 201-208.

Zaidi, S. S., D. P. Martin, I. Amin, M. Farooq and S. Mansoor. 2017. Tomato leaf curl New Delhi virus: a widespread bipartite begomovirus in the territory of monopartite begomoviruses. Mol. Plant Pathol. 18: 901-911.

Zamir, D., I. Ekstein-Michelson, Y. Zakay, N. Navot, M. Zeidan, M. Sarfatti, Y. Eshed, E. Harel, T. Pleban, H. Van-Oss, N. Kedar, H. D. Rabinowitch and H. Czosnek. 1994. Mapping and introgression of a tomato yellow leaf curl virus tolerance gene, Ty-1. Theor. Appl. Genet. 88: 141-146. 